\title{
"On the way we conference" [opinon]
}

Wiebke Drenckhan

LPS, Université Paris-Sud, Orsay (France)

$\mathrm{Y}$ ou are at (yet) another one of these big conferences where - unless you paid the 75 Euro for the conference dinner you spend your night leafing through a book of abstracts of a size which poses a serious thread to the weight limit on the flight back.

Over the years you have developed a sophisticated point system to help you decide efficiently which of the densely packed parallel sessions to go to, and especially which ones to skip, in order to have some time to discuss with colleagues (who will have to be convinced first to skip the same talks). You also have a map of the conference venue ready in which you have drawn in multiple colours the connections between rooms which minimise the time it takes you to run between them. Now that you are here you might as well make the most of it!

You have come because you have been invited to give a talk (and you are proud of it). You have come because you have always gone. You have come because your colleagues always do, because it is necessary to add another bullet point in your $\mathrm{CV}$ proving your research activity, because you were afraid to miss out on something, because you hoped that this one would prove more useful than the previous one,... You have come because it is in a nice location and you will stay on with your family for two more days for that long overdue holiday that you had promised them when you did not have time to come home for dinner because you were preparing for conferences.

We have many reasons to go to conferences! But do we go for the right ones?

Conferences have been around for hundreds of years and for very good reasons. They are intended to allow easy communication, i.e. the exchange of ideas and the formation of collaborations so essential to progress in science. As such they are vital in developing a sense of the community in which we need to navigate comfortably. Conferences are also meant as means of inspiration, and they aim to provide opportunities for ideas to crash into one another to pave the way for those which prove the most appropriate in describing (and manipulating) the natural world.

But are our conferences really living up to this?

With the availability of the phone at ever dropping rates and the explosion of the internet and its capacity - which not only brought along email and video conferences, but also very rapid publishing - conferences have become just one of many means of communication in science.

Nowadays, when a colleague at the other end of the world makes an exciting discovery, we can know of it within a few hours, can discuss it via a video conference and have a paper written and submitted within a few days. Within a few weeks it can be published (provided that Nature or Science agree that it is exciting), or otherwise within a few months (provided the referees agree). Or, we simply put it on the web. Those with a dislike of digital communication can spend money from one of the several travel grants they have and benefit from the boom of low-cost airlines to go and see those colleagues personally.

As a consequence, we generally know rather well what is going on in our field. And we can also routinely keep ourselves up to date about the current affairs in any other field thanks to the vast amount of electronic search engines and journals (possibly even with "free" access to articles, if recent developments continue).

What a change compared to even 50 years ago, when scientists were communicating with their colleagues abroad via snail mail in elegant handwriting, one at a time!

What has changed very little, however, is the way we "conference" in this new ICT era and the way we spend summers and research money touring conference hotels and parallel sessions, just to get lost in the hundreds of overspecialised PowerPoint presentations that run non-stop throughout the whole day; and trying to toss back the terrible coffee, whilst flying through hundreds of posters in the few hours available before the next lot is put up...

Conferences are absolutely essential for exactly the reasons I have mentioned before. But I feel that we have got stuck in an old-fashioned routine in the way we run them. I would therefore like to suggest that we pause for a moment, step back and rethink what role conferences could and should play in present-day science communities and how they can really fill the gaps which modern means of communication and travel cannot provide. In my opinion, the key gap to be filled is that of human contact and interaction!

In this spirit I believe that whatever shape conferences take, it is absolutely essential to avoid parallel sessions and to provide sufficient time for participants to meet and to discuss. (The currently available two minutes for questions after each talk mostly serve the purpose of profiling individuals in the audience or simply of running between parallel sessions.)

Beyond this, I see two particularly important functions that conferences should fulfil. And they should be clearly dedicated to one or the other without overlap.

\section{Depth and detail}

We certainly need small conferences with a focus on a narrow theme where plenary-type overview lectures of current progress and specific talks/posters/etc. are regularly followed by discussions on a larger scale and between individuals. (Which is basically what conferences used to be like, did they not?)

\section{Across boundaries}

Generally, scientists apply similar fundamental principles to the description of different fields, which leads to the not-sosurprising fact that similar methods are commonly developed independently and simultaneously in different fields. Hence, thematically wider-scale conferences with only plenary-type presentations by experts can not only ensure transfer of 
knowledge and technologies across boundaries, but can also provide the inspiration that is often triggered by interdisciplinary contacts and collaborations.

In all cases it is absolutely essential that speakers are (made) aware of their target audience and that they adjust their presentation accordingly. I find it less embarrassing to bore $50 \%$ of the audience than to lose the same number after the first few minutes.

In general, scientists should be intrinsically interested in attending and enjoying conferences even without presenting their own research work. The current trend, namely that speakers appear only for the day of their presentation, speaks for itself and is completely beside the point of such meetings.

Such trends are amplified by the fact that the number of conferences each of us could attend every year seems to increase exponentially, with new conferences being announced continuously, whilst "old ones" rarely disappear. (Unfortunately, Darwin's law does not seem to apply to conferences.) As a result, scientific excellence at conferences is increasingly rare and far between, a trend we should re-consider valuing scientific quality over quantity.

I do not believe that such considerations can (nor must) lead to the "optimal answer" or to the "ideal recipe" regarding the way we conference. The "recipe" will and should always depend on the specific aim and communities concerned, and it also needs to find its place between other scientific meetings, such as workshops or schools. What is more important is that conference organisers develop the habit of critically questioning and consequently adjusting the way things are done to integrate them naturally and fruitfully into the progress and overall "well-being" of our community.

Why not be braver and experiment a little more with conferences? People might argue (rightly, I believe) that it is important to know what they are getting themselves into before signing up for a conference. But instead of providing such transparency by making all conferences alike, we should use the power of digital communication in advance of the conference, i.e. by expressing the conference targets and procedures clearly on the web.

Hanging on to the traditional format of conferences, without finding very good reasons to do so, is - according to my opinion - a waste of taxpayers' money and researchers' time. As it is, too many conferences serve mostly the tourism industry (which gets to feed, sleep and transport all those hundreds of scientists and their spouses) and the CVs and egos of the conference organisers. And not to forget about those politicians who arrive for every opening session to announce the conference location as internationally leading in terms of scientific output, technological innovation and, of course, natural beauty. -

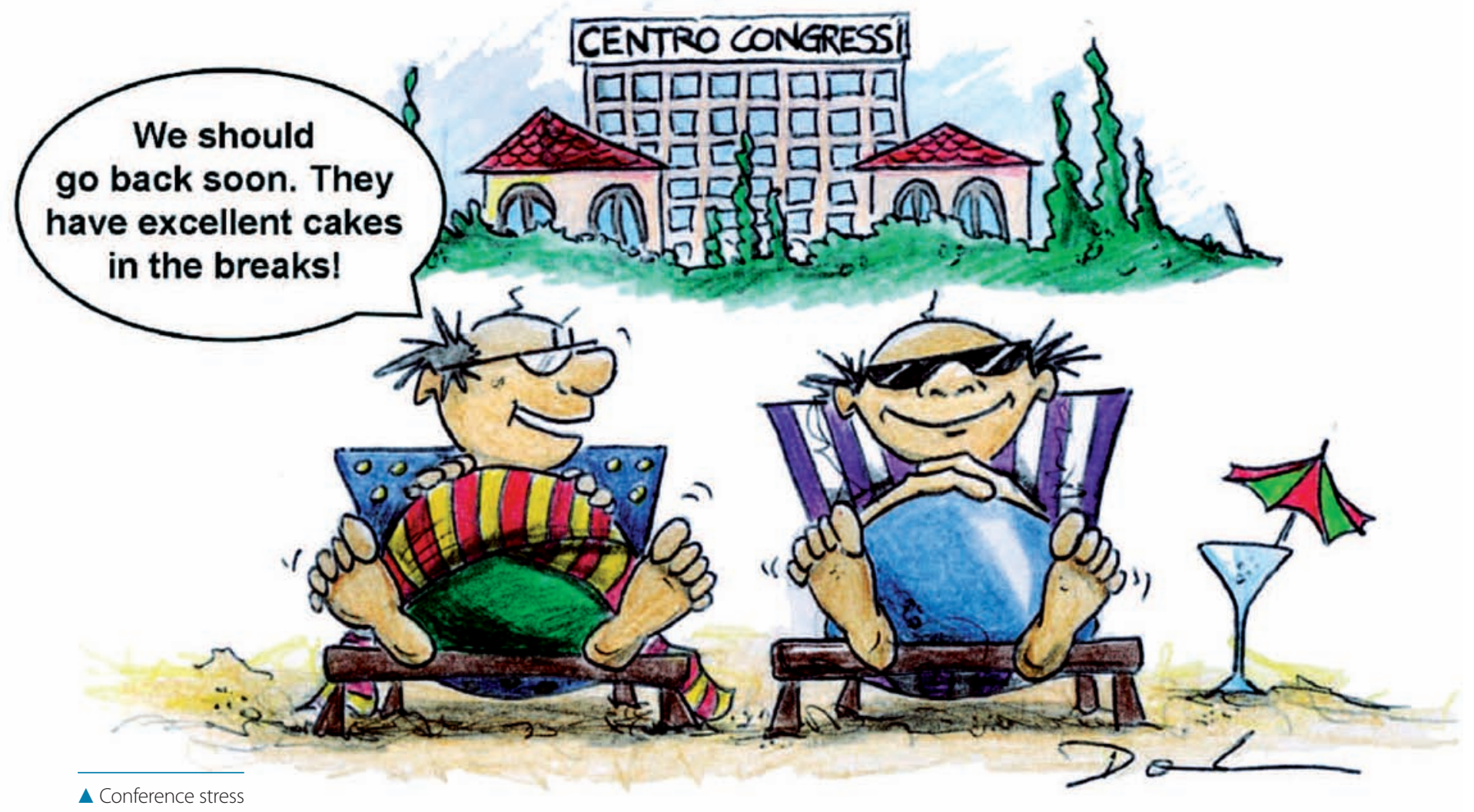

